\title{
5E INSTRUCTIONAL MODEL: A CONSTRUCTIVIST MODEL FOR TEACHING CHEMISTRY AT HIGHER SECONDARY LEVEL
}

\author{
Muhammad Abid Zia \\ Associate Professor, \\ PAEC Education Center, \\ Punjab, Pakistan \\ Email: muhammadabidzia@gmail.com

\section{Farkhunda Rasheed Choudhary} \\ Assistant Professor, EPPSL Department, \\ Allama Iqbal Open University, \\ Islamabad, Pakistan \\ Email: farkhunda.rasheed@aiou.edu.pk
}

\begin{abstract}
Concepts of Chemistry are complex in nature and are hard to comprehend. To teach these complex concepts effectively, a modern constructivist instructional model can be a more appropriate choice. This study aimed to compare the academic achievement of students on posttest and retention test, taught through the 5E instructional model at the higher secondary level. The research design was pretest-posttest equivalent groups design. The sample consisted of 60 randomly selected students from the accessible population and was divided into two equivalent groups based on their pre-test score. The experimental group's students were instructed through the 5E instructional model and the control group students were taught through the traditional lecture method for five weeks. Data was analyzed applying t-test at .05 level of significance. Data analysis showed that the experimental group outscored significantly than control groups on post-test as well as on retention test exhibiting the effectiveness of the 5E instructional model. It was concluded that although the 5 E model requires more resources and time especially at the higher secondary level, however, it is recommended that this model must be used to teach Chemistry at the higher secondary level for improving academic achievement and better retention of knowledge.
\end{abstract}

\section{KEYWORDS}

Chemistry learning, Constructivist approach, 5-E model, Retention

\section{INTRODUCTION}

Chemistry is considered a complicated and difficult subject not only in Pakistan but 
all over the world. Many types of research described that it is always a big task for the students to have better academic achievement in this subject. Although Chemistry is a very essential and primly important subject, most of the students who come from junior grades have an inadequate understanding of Chemistry which makes it more challenging for them. The discipline of Chemistry had been considered very hard by numerous researchers, teachers, and science educators. Another dilemma is that the mainstream of the educators at the secondary level utilize the autocratic teaching approach. There is a need for deep-seated change in Chemistry instruction to make it simple to understand and easy to comprehend. Roig (2008) said that learner's academic performance can be boosted by applying a robust and active design of learning and teaching. It is human nature that they try to solve the problems faced by them and find suitable solutions with the passage of time. The discovery of new teaching techniques for Chemistry is the basic need for its effective learning. Different instructional models guide possible solutions. But before going to the solution it is necessary to understand the actual problems lying behind. According to Osborne and Collins (2000), "during the past decade, the interest and achievements of chemistry students have declined." Initially, we must focus on the reasons why Chemistry is taken as a hard subject. One can meet many students which blame Chemistry as a big barrier in their academic achievements. Gabel (2002) stated that "what I have learned in teaching at all levels is that most students want to excel in science until they are discouraged by failing to understand it" (p.17). One reason for Chemistry as a "problematic subject" is "chemists communicate in a highly elaborated alphabetic and symbolic language" (Sliwka, 2003, p. 24). There are many symbols, molecular formulas, formula units, etc. which are needed to be in the mind while learning Chemistry. Therefore, "the language of Chemistry has to be constructed on an abstract and less familiar knowledge base" (Taber, 2009).

The chemical reaction is a topic where students have misconceptions in their understanding, because "some of the major problems in teaching and learning Chemistry are encountered in the very first stages of an elementary Chemistry course" (de Vos \& Verdonk, 1986, p. 972). Treagust and Chandrasegaran (2009) stated that "to be able to explain chemical reactions, students will have to develop models of the submicroscopic particles of the substances that undergo rearrangement to produce the observed changes" (p. 153). There are three sources of difficulties that students can have during learning process. Johnstone (1984) explained, "nature of the science itself makes it inaccessible, the methods by which we have traditionally taught raise the problems and the methods by which students learn are in conflict with either or both of the above".

Ross, Lakin McKechnie \& Baker (2010) stated that it is difficult for the student to apply the facts of Chemistry and use their knowledge for the solution of real-world 
problems. For instance, students were unable to use any chemical reaction in their own small production plants. These students were not able to tell even the composition of their body parts.

Formation of concepts requires active psychological involvement and mental effort of the learners. The instructional model is certainly related to the concept assimilation of the students of science, particularly Chemistry. Concepts of Chemistry are complex in nature and are hard to comprehend. To teach these complex concepts effectively a modern constructivist instructional model can be a more appropriate choice. Constructivist instructional models such as learning cycles give emphasis on learning based on students' active participation and their involvement in different phases for building their concepts. Thus, this study proposed to determine the strength of the $5 \mathrm{E}$ instructional model (5E learning cycle) on the learning of Chemistry at a higher secondary level in contrast to the traditional model of education i.e., lecture method. The failure or incompetence of the traditional lecture method for adequate academic achievement in chemistry provides the rationale of the present study.

\section{LITERATURE REVIEW}

A constructivist approach is a better option to convert complex abstract ideas of Chemistry into concrete concepts. Springer (2014) suggested that the use of physical models improves the understanding of Chemistry in the years back into the history of science, but molecular modeling is found to be more effective to enhance the achievement of the students in organic Chemistry. They can understand the structure of organic compounds as well as other properties shown by those compounds in an excellent way when they use molecular models.

Research on the learning and teaching of Chemistry have revealed that vivid discrimination is there between girls and boys. It has been seen that girls are good at memorization as compared to boys. Similarly, the performance of boys has reported well in practical performances. (Wigfield, Eccles, Schiefele, Roser, \& Devis-Keen, 2006) think that where boys are self-confident about their role in controlling the world and solving the problems; girls show more interest in learning Chemistry, Physics, and Mathematics likewise. Girls are found to be more hardworking and passionate in some aspects like verbal communications. On the other hand, boys have a better grip on practical performances. Although a teacher has an equal expectation of performance from both the genders and hence should provide a level playfield.

Mari (2012) after the study reflected, “...the process-based instruction tends to have stimulated higher reasoning gains in the female subjects than the male subjects. Use of process-based learning tends to benefit female students more than males" (p.996). It is noteworthy to identify that everyone has his own understanding of the various 
phenomenon around him in the world. Different individuals interpret the same surroundings in different ways because they have their personal inspirations and experiences. Alsop, Bencze \& Pedretti, (2005) argued that learning is a phenomenon that is seriously inhibited by a variety of factors including the learner's cognitive ability. The cognitive abilities of different learners seriously confine learning like preexisting mental constructs.

The creation of suitable terms is vital in Chemistry as it helps in problem-solving and situations can easily be understood by using the expertise of science. As stated by Ellis (1978), concept learning involves responding to the pertinent parts of the conceptual framework and ignoring the inappropriate fragments in categorizing events. Teachers expect students of Chemistry to pick the concepts in few moments with certainty just after they have been taught. But this is not the case as cited by Haith \& Benson by Santrock (2006) that concepts seldom are learned suddenly but take a chain of partial accomplishments leading to increasingly comprehensive understanding. So, it is unfounded to expect output from the student just after conveying a lecture. Once students can build the concept strongly these, strongly built concepts prove to be a launching pad for the flight of good understandings.

Iqbal (2003) described that students face difficulties in learning chemistry due to their curriculum. According to him, the curriculum must be good enough to provide the necessary required skills to the students essential for progress in science.

The constructivist methodologies of teaching orbit around the philosophy that humans comprehend the knowledge constructed on their own. Learning through experience has a strong impact as learners use their cognitive abilities. Woolfolk (2007) described, "Constructivism is best understood in terms of how individuals use information, resources, and help from others to build and improve their mental models and their problem-solving strategies".

Scaffolding is a widespread constructivist teaching method. The scaffolding approach is a learning strategy resemble with metacognition of problem-solving techniques. The teacher visualizes how the students can be directed to practice their skills to learn. Activities are used as a valuable strategy for learning. The teacher guides the students for his activities at the start and when he feels the learner is improving and can do some activities on his own, then the teacher tells him to move forward and now the teacher only assists the learner. The teacher gives the learners a simpler situation or problem to apply his previous knowledge and then students can handle a new situation or task successfully. Normally trainers use scaffolding support comprising "modeling, coaching, contextual support, etc.". 
The aim of this study was to explore the effect of the 5E teaching model on the performance of higher secondary chemistry students. The effect of the independent variable (i.e., 5E instructional model) was assessed on the dependent variable (i.e., academic achievement) of the students. Many constructivist approaches like scaffolding, collaboration, inquiry-based teaching, etc. are reported to be effective in science teaching. Constructivism is based on social development theory of Vygotsky and cognitive development theory of Piaget. If students create their own knowledge, their concepts are stronger, and their academic achievement becomes better. Students of higher secondary level of this era are very active and they cannot be taught without involving them directly in learning activities and knowledge construction process.

The learning cycle developed by Robert Karplus had three sequential phases named as exploration, concept introduction, and concept application. With the passage of time, these phases had been expanded to five and had been transformed into a $5 \mathrm{E}$ learning cycle instructional model: Engagement, Exploration, Explanation, Extension, and Evaluation. Every instructional model/learning cycle relies on the consistent inductive order of instruction irrespective of number of phases. Engagement is the first phase in almost all the learning cycle/ instructional model. The purpose is to create curiosity to investigate the scientific facts. Throughout the exploration phase, the teacher performs the role of a facilitator, conveying instructions about the experiment, and providing materials. After the exploration, the teacher organizes a dialog or discussion, and learners discuss their observations with their class fellows. At this stage, students try to link their experiences to the target concept with the help of their teacher in scientific terms. After the construction of the concept, the teacher involves the students in new activities to encourage them in applying the newly acquired understanding to new situations.

Bybee (2009) suggested in his paper that in this era teachers must make the concepts clearer by progressing from wide goals to definite objectives. Duran \& Duran (2004) cited Bybee \& Landes (1990), "although there are several variations of learning cycle models, the 5E instructional model is more appropriate model to support inquiry-based teaching. The use of this model is also very effective in many science education professional development programs".

Metin, Coskun, Birisci, \& Yilmaz (2011) concluded after their study, "The prospective teachers believed that in the constructivist learning environment, students want to learn new knowledge. 5E instructional model helps the students to concretize topics. 5E model helps teachers about what to teach and how to teach" (p. 419).

Retention of the concepts is also enhanced using constructivist models especially the learning cycle model as various related research support this fact. So, according to 
Fazelian \& Soraghi (2010), "In general, 5E instructional design is effective in increasing learning level of students, learning quantity of science lessons and increase the level of retention of students" (p.142). Bybee (2009) reviewed his model for its adaptability in the $21^{\text {st }}$ century. He stated, "Adaptability is the ability and willingness of individuals to cope with uncertain, new, and changing conditions. Learning new tasks, technologies, and procedures seem particularly applicable to opportunities for learning in science classrooms". He also explained that problem-based learning on rational thinking might be endorsed by using the $5 \mathrm{E}$ instructional model and students could be prepared to solve those problems that are out of routine. He further argued that the 5E instructional model enhanced the attitude towards the scientific approach and its self-management character made it more interesting for the learners. This selfdriven character of the instructional model favored the learners to have a masterybased on personally created and managed scientific understanding.

Ürey \& Çalik (2008) quoted, "science students' misconceptions are not completely amended by means of only one conceptual change method, rather using different methods embedded within the 5E model may be more effective in enhancing students' conceptual understanding and also may eliminate all students' misconceptions" (p.2). The instructional model under debate can be made more efficient and effective by blending it with other latest techniques. Daşdemir (2017) claimed, "5E instructional model blended with animations proved to be more successful and efficacious not only for conveying science concepts but also for enhancing the scientific aptitude of the students" (p.21).

The whole review of the related literature can be recapitulated in brief. Literature review confirms that Chemistry is a difficult subject comprising of many basic concepts that are abstract in their description. So, Chemistry learners may develop many misconceptions. Along with these complex ideas many process skills are needed in Chemistry. Therefore, Chemistry instruction may be the most effective and best one if it is based on a constructivist model in a pure constructivist environment. 5E instructional model that is an inquiry-based constructivist approach, is helpful in scientific learning specifically for the learning of Chemistry. 5E instruction has interlinked progressive phases of learning and constructing individual knowledge through previous and current experiences. Hence it may be supportive for the construction of concrete concepts, for mastering applied skills, and for the elimination of the related misconceptions. Therefore, this research study was maneuvered to find the effectiveness of the 5E instructional model for enhancing the academic achievement of the learners in the subject of Chemistry in the present era of competition. 


\section{RESEARCH OBJECTIVES}

1. To compare the academic achievement of the students in chemistry taught through the $5 \mathrm{E}$ instructional model and traditional lecture method at the higher secondary level. 2. To compare the academic achievement in the chemistry of male as well as female students taught through the 5E instructional model and traditional lecture method at the higher secondary level.

3. To explore the retention of concepts of the students taught through the 5E instructional model and traditional lecture method.

4. There are some studies that show the disparity of gender on the achievement of Chemistry. Therefore, the researcher was concerned to distinguish the effectiveness of said instructional model on Chemistry achievement of both genders.

\section{RESEARCH METHODOLOGY}

In this study, a pre-test post-test equivalent group research design was adopted. Sixty students including 40 boys and 20 girls were taken as the sample. A total of ten topics from the $1^{\text {st }}$ Year textbook was selected for the research. The researcher prepared an achievement test involving fifty multiple-choice questions. This achievement test was checked for reliability. The test was found reliable. This test was then conducted as Pre-test. Sixty students of XI were divided into two equivalent groups based on their score on this pre-test. Lesson plans were prepared from selected topics. Both experimental and control groups consisted of 30 students. Both groups were instructed through two different methods for 5 weeks. The traditional method means the lecture method of instruction was used in the control group courses, while the 5E instructional model was employed for conducting the lessons to the experimental group. After the completion of treatment, a post-test was conducted. The experimental group as well as the control group participated in the post-test. A retention test was also conducted after 4 week's break. The data analysis was carried out once again. Scores were compared through a t-test application at 0.05 significance level and comparing the table values given on the corresponding degree of freedom.

\section{RESEARCH FINDINGS}

The data were organized, and statistical tests were applied to analyze and interpret the data. The groups were compared using the mean values, then standard deviations were computed for each group to infer and analyze the collected data. The $95 \%$ level of confidence at 0.05 alpha value was used for this study.

Table 1

Comparison of Achievement Scores of Experimental and Control Groups on Pre-Test

\begin{tabular}{lllllll}
\hline Groups & $\mathrm{N}$ & $\mathrm{X}$ & $\mathrm{SD}$ & $\mathrm{SEM}$ & $\begin{array}{c}\text { Calculated } \\
\text { " } t \text { "Value }\end{array}$ & $p$-Value \\
\hline
\end{tabular}




\begin{tabular}{lrrrrrr} 
Experimental & 30 & 24.10 & 6.025 & & & \\
& & & & 1.56 & 0.1064 & 0.458 \\
Control & 30 & 24.27 & 6.113 & & & \\
\hline \multicolumn{1}{c}{$\mathrm{df}=58$} & & Diff of Means $=0.17$ & $\mathrm{p}>0.05$ &
\end{tabular}

Table 1 shows that the calculated " $t$ " value $(0.1064)$ is less than the tabulated value at 0.05 (2.045) showing no significant difference between the mean scores of experimental and control groups on pre-tests. It can be inferred that both groups were truly equivalent before the start of treatment.

Table 2

Comparison of Mean Scores of Experimental and Control Groups on Post-Test

\begin{tabular}{lcccccc}
\hline Groups & $\mathbf{N}$ & $\mathbf{X}$ & SD & SEM & $\begin{array}{c}\text { Calculated "t } \\
\text { Value }\end{array}$ & p-Value \\
\hline Experimental & 30 & 39.2 & 5.83 & & & \\
Control & 30 & 35.5 & 6.43 & & & \\
\hline $\mathrm{df}=58$ & Diff of Means $=3.7$ & $\mathrm{p}<0.05$ & & \\
\hline
\end{tabular}

Table 2 shows the mean scores on the post-test of the control and experimental group as 39.2 and 35.5, respectively. The difference between the two mean scores was 3.7 at a .05 level of significance. It describes that the learners of the experimental group produced a better achievement on post-test than the learners of the control group. It also indicates that the 5E instructional model had a better effect on the academic achievement of the learners as the experimental group performed better in the given concepts of chemistry on the post-test.

The experimental and control groups were segregated into two parts based on gender to see the effect of this demographic factor. As the members of the same gender of the experimental group were compared with the same gender of the control group, so it will provide evidence of quantitative measure of the effect of the instructional model on academic achievement of the learners. This comparison is presented here:

\section{Table 3}

\section{Comparison of Mean Scores of Girls of Experimental and Control Groups on Post-Test}




\begin{tabular}{lcccccc}
\hline Groups & $\mathbf{N}$ & $\mathbf{X}$ & SD & SEM & $\begin{array}{c}\text { Calculated " } \boldsymbol{~} \text { " } \\
\text { Value }\end{array}$ & $\boldsymbol{p}$ Value \\
\hline $\begin{array}{l}\text { Girls of } \\
\text { Exp. Group }\end{array}$ & 10 & 42.20 & 5.01 & & & \\
$\begin{array}{l}\text { Girls of } \\
\text { Control Group }\end{array}$ & 10 & 37.50 & 4.93 & & & \\
\hline \multicolumn{1}{c}{$\mathrm{df}=18$} & Diff of Means $=4.7$ & $\mathrm{p}<0.05$ & & \\
\hline
\end{tabular}

Table 3 explains that girls or female learners of the Experimental group achieved mean scores of 42.20 on the posttest and girls or female learners of the control group achieved mean scores of 37.50 on the posttest. The difference between the two means was calculated to be 4.7 and it was significant at the .05 level and $p<0.05$. Therefore, it also indicates better performance of the females of the experimental group on post-test as compared to the female learners of the control group.

In the next table 4 , both groups are compared with reference to their boys or male students. Their achievement scores were compared like the previous comparison to judge the effectiveness of the instructional model for boys or males of both groups.

Table 4

Comparison of Mean Scores of Boys of Experimental and Control Groups on Post-Test

\begin{tabular}{|c|c|c|c|c|c|c|}
\hline Groups & $\mathbf{N}$ & $\mathbf{X}$ & SD & SEM & $\begin{array}{l}\text { Calculated } \\
\text { " } t \text { " Value }\end{array}$ & $p$ Value \\
\hline $\begin{array}{l}\text { Boys of } \\
\text { Exp Group }\end{array}$ & 20 & 37.70 & 5.74 & \multirow[b]{2}{*}{2.02} & \multirow[b]{2}{*}{1.586} & \multirow[b]{2}{*}{0.0607} \\
\hline $\begin{array}{l}\text { Boys of } \\
\text { Control Group }\end{array}$ & 20 & 34.50 & 6.96 & & & \\
\hline
\end{tabular}

Table 4 explains that boys or male learners of the experimental group achieved mean scores of 37.70 on the post-test and boys or male learners of the control group achieved mean scores of 34.50 on the post-test. The difference between the two means was 3.2 and it was not significant at the .05 level and $p>0.05$. It implies that the boys of the experimental group did not show a significantly better performance on the post-test than the boys of the control group. Although this difference was not significant still, they had shown a bit higher mean score that may be considered slightly better performance. But at the same time interpreting Table 3 provides the evidence that girls of the experimental group had a strong effect on the $5 \mathrm{E}$ instructional model. 
A retention test was also conducted after four weeks to assess the effectiveness of the instructional model for the retention of the knowledge of both experimental and control groups. So, for the sake of evaluating and comparing their achievement in the retention test the table 5 has been developed.

Table 5

Comparison of Mean Scores of experimental and Control Groups on retention Test

\begin{tabular}{lcccccc}
\hline Groups & $\mathbf{N}$ & $\mathbf{X}$ & SD & SEM & $\begin{array}{c}\text { Calculated } \\
\text { “ } \boldsymbol{~} \text { " Value }\end{array}$ & $\boldsymbol{p}$ Value \\
\hline Exp Group & 30 & 37.63 & 6.46 & & & \\
Control Group & 30 & 32.70 & 6.70 & & & \\
\hline \multicolumn{1}{c}{$\mathrm{df}=58$} & Diff of Mean $=4.93$ & $\mathrm{p}<0.05$ &
\end{tabular}

Table 5 explains that learners of the experimental group achieved mean scores of 37.63 in the retention test and learners of the control group achieved mean scores of 32.70 in the retention test. The difference between the two means was 4.93 and this difference was significant at the .05 level and $p<0.05$. Therefore, it indicates that the experimental group had revealed significantly better performance in the retention test also than the control group. In addition to this difference is more significant and becomes higher so it is proved that the experimental group gave a further outstanding performance in the retention test. So, the experimental group has shown that the 5E instructional model has also a strong effect in terms of retention of acquired knowledge.

Statistical analysis is a complicated interpretation of the figures and scores of two groups hence it is difficult and inconceivable for some people who may be interested to see the analysis in a layman style. For this purpose, the researcher would like to represent recorded data which is tabulated in an ordinary and conventional style by using only the mean scores of the groups.

Table 6

Overall Comparison of Mean Scores \& Gain in Mean Scores of Experimental and Control Groups

\begin{tabular}{ccccc}
\hline Mean & Mean Score Mean Score & Increase in & Decrease In \\
Mean Score & Mean Score & Mean Score \\
Retention & from Pre- & from Post to \\
fores $\Rightarrow$ & Pre-Test & Post Test & $\begin{array}{c}\text { Test } \\
\text { Test to Post }\end{array}$ & $\begin{array}{c}\text { Retention } \\
\text { Test }\end{array}$ \\
\hline
\end{tabular}




\begin{tabular}{cccccc}
\hline \multicolumn{1}{c}{ Groups } & Column A & Column B & Column C & $\begin{array}{c}\text { Column D } \\
(\mathrm{B}-\mathrm{A})\end{array}$ & $\begin{array}{c}\text { Column E } \\
(\mathrm{C}-\mathrm{B})\end{array}$ \\
$\begin{array}{l}\text { Experimental } \\
\text { Control }\end{array}$ & 24.1 & 39.2 & 37.63 & 15.1 & -1.57 \\
Difference & 24.27 & 35.5 & 32.7 & 11.23 & -2.8 \\
& -0.17 & 3.7 & 4.93 & 3.87 & 1.23
\end{tabular}

The above graph shows the overall comparison. The difference of mean scores progressively increases from pre-test to retention test through post-test, which is another indicator of better achievement of the experimental group over the control group.

On the whole results of the study validate that the 5E instructional model enhances achievement and knowledge retention in the subject of Chemistry at a higher secondary level.

\section{CONCLUSIONS AND DISCUSSIONS}

The performance of experimental group was found better than the control group on the post-test. The female students of the experimental group performed better as compared to the female students of the control group. Thus, overall, this instructional model was confirmed to be a more powerful instructional model for Chemistry teaching at a higher secondary level.

This instructional model assured students' active participation in the teaching-learning process indebted for better academic achievement of the learners. Although male students of the experimental group did not show significantly better performance in the post-test than the male students of the control group but still had better mean scores than male students of the control group.

The performance of students of the experimental group in the retention test was also better than students of the control group. So, the retention of knowledge of the experimental group was also found better than the control group. It implies that retention of knowledge was also far better in the $5 \mathrm{E}$ learning cycle instructional model showing the supremacy of this constructivist approach for long-lasting concepts.

Therefore, it is concluded that Chemistry instruction based on the 5E instructional model is suitable for concept formation. Therefore, this model augmented the level of 
achievement in experimental groups' students on post-test as well as an enhanced level of concept and knowledge retention.

The study was presented mainly to find the effectiveness of the $5 \mathrm{E}$ learning cycle model frequently recognized as the 5E instructional model in which students are encouraged to create their own constructs based on their learning experiences. As it has been discussed in this research thesis that Chemistry is a discipline of science that contains various concepts that are not easy to visualize as these are abstract ideas and it is a very complex task to make abstract ideas concrete. The teaching of Chemistry to a higher secondary level is a challenging task and the traditional teaching model is not efficient to teach this technical subject.

The findings or results of the present study underpin and reinforce the findings of Kilavuz, 2005; Atilla, 2007 and Vosniadou, 2007. The findings of the presented study support that student's Chemistry achievement can be enhanced by using the 5Es of the instructional model. In general, most of the students think that Chemistry is a group of complicated ideas to learn and remain worried about their success in comprehending the concepts of Chemistry. Therefore, understanding these concepts becomes more difficult for them. Furthermore, concept assimilation through instruction is a challenging task because concepts become deeply rooted in the students' minds and their formation requires several observations and numerous personal experiences. The basis of $5 \mathrm{E}$ instructional model is the constructivist approach in which it is the basic job of the teachers to create the environment to engage the learners in such a way that his previous knowledge is bridged with the topic and learner can create his own constructs. The newly created constructs would be appropriate and free of fallacies and alternative conceptions provided the instructor knows very well the learning process and facilitates the students during all phases of the $5 \mathrm{E}$ instructional model.

The present study supports the results of Acish, Yalçin, Turgut, (2011) who argued that students can explore and find out the core concepts of the content on their own by questioning, searching, using prior knowledge, linking it with daily life, assembling apparatus, and analyzing the experiment on their own. So, the 5E instructional model is a successful teaching model. Change in the conceptual framework of students should occur in the 5E instructional model and the teacher helps his students to create their own concepts through a series of steps. The government of Pakistan also recognized the significance of conceptual teaching. Zaidi and Rahman (2008) stated in Pakistan, Government authorities are determined to ensure the implementation of concept-based teaching. The curriculum has been thus developed to highlight that concept formation has core importance in the teaching of science instead of overfilling the students with needless and often unrelated details. A vision emerged from the findings reveals that the $5 \mathrm{E}$ instructional model is an efficient and useful teaching model for the 
strengthening of previous concepts of students and for the understanding of new original and complex concepts.

The results of this research are comparable with the findings of Ceylan (2008) who commented that conceptual change is made easy by a teaching model that uses a learning cycle, built on constructivism, and includes basics of the 5E instructional model. This learning cycle is one of the important latest versions of the instructional model. Instruction should be intended to clarify misconceptions of the students to lodge new thoughts and ideas which are converted into concepts. One of the important benefits of the $5 \mathrm{E}$ instructional model provides a suitable base that creates reliable consistent mental structures. A cluster of new appropriate concepts is constructed on the foundation of reliable mental constructs or structures.

The findings of Yavuz, 2005; and Onder and Geban, 2006 described that instruction based upon the conceptual change approach is better than traditional methods in rectifying misconceptions and promoting understanding of students regarding science concepts. Results of this study exposed that the traditional method is a weak instruction model as it provides knowledge of words only where students were required to grasp only the scientific truths as described by teachers and recall these facts whenever required. On the other hand, the $5 \mathrm{E}$ instructional model supports procedural knowledge i.e., knowledge about knowing how to do certain activities. In the 5E instructional method, the teacher starts the lesson after checking previous knowledge with some questions. By bridging previous knowledge to new ideas, the teacher explains and clarifies these ideas. By working together with the teacher and class-fellows, learners corrected some misconceptions also. Although students work and learn autonomously and independently at the same time teacher put forth many queries to check the correctness of students' responses. This might produce a difference in the achievement of experimental and control groups. Although control group students were able to name some facts, they failed to apply these facts to other daily-life phenomena. At the same time, experimental groups' learners were found more confident to apply their acquired skill in a better way.

Several studies had shown a positive relationship between the 5Es of the learning cycle and students' achievement. For example, Cetingul and Geban, 2005; Baser, 2006; Gardon, 2007; Calık, Ayas, Coll, Ünal andCoştu,2007; Canpolat, Pınarba, Bayrakeken and Geban, 2009; and Ozmen, Demircioglu and Demircioglu, 2009; Shaheen and Kayani, 2015 favored the view "Constructivist approaches were found to be successful for the formation of scientific concepts" as cited by Khan, (2011). This study also gives 
comparable judgment that the 5E instructional model presented an encouraging impact on students' achievement. The results also indicated that the 5E instructional model appeared to be approved for enhancing concepts building ability and for the removal of misconceptions even for the learner of less cognitive ability.

The present study has shown an unlike a piece of evidence that the performance of boys of experimental and control groups was the same on posttest scores, unlike the girls of the experimental group who performed significantly better than girls of the control group. Although there are studies like Yavuz, 2005; Baser, 2006 and Salami, 2007 who proved that interaction between gender difference and treatment did not make a significant contribution in the variation of academic achievement as cited by Khan (2011). But the findings of this study establish that a significant difference existed in academic achievement between male and female students with respect to achievement in Chemistry through the $5 \mathrm{E}$ instructional model. This may be because girls take more interest in procedural educational activities as Mari (2012) stated, "that process-based learning is more beneficial for females than males.

The overall results of this research study were also favored by Kilavuz (2005) who gave the conclusion that the $5 \mathrm{E}$ instructional model is a foundation of a significantly improved attainment of scientific conceptions than traditionally planned instructional method. The scientific procedural skills were also improved by means of the $5 \mathrm{E}$ instructional model. Teacher-assisted inquiry helped the students to produce their own ideas and explained the facts based on their experiences during different procedures and phases of the learning cycle.

The overall findings of this research are strengthened by the findings of 31 studies present between 2006 and 2016 regarding science lessons where the 5E instructional model was found to have an effective impact on the academic achievement of students as compared with the traditional method of teaching.

Hence, the presented study demonstrated that students had a weak understanding of the concepts of Chemistry as pr test scores were significantly low. By means of the 5E instructional model, learners did well in the achievement test and produced good achievement on Chemistry post-test due to added clarity of concepts because this was instigated through the stages of the $5 \mathrm{E}$ instructional model.

\section{RECOMMENDATIONS}

Keeping in view the findings and conclusions of this research, following recommendations are presented hereafter. 
1. It is recommended that the $5 \mathrm{E}$ instructional model is proved to be supportive to the learners for the construction of their own knowledge which is long-lasting and for teachers to convey and build clear and stronger concepts of Chemistry.

2. In 5E instruction, students are encouraged to construct their own concepts by using various laboratory techniques that enhance procedural knowledge so teachers of Chemistry should employ this teaching model. 5E teaching model might be used to alter the old and ineffective concepts to new and conceivable concepts. This model can easily bridge the existing and new knowledge in the first two phases. This bridging would result in more meaningful learning.

3. The instructional model with 5Es may be employed to modify the conventional classroom's environment to a modern constructivist classroom where students can use their knowledge to solve their problems. It will enable them to solve real-life problems and develop multifaceted skills with accurate concepts. As declarative knowledge is not sufficient in science teaching, therefore, other skills should also favour procedural knowledge and the $5 \mathrm{E}$ instructional method helps to facilitate developing more skills.

4. 5E instructional model persuades the practical handling of the Chemistry gadgets and apparatus which make the learner participate in creating new concepts. Therefore, teachers may be trained to master the $5 \mathrm{E}$ instructional model for imparting the procedural knowledge to the students.

5. As more time is needed for this $5 \mathrm{E}$ instructional model so some complicated concepts of higher secondary level must essentially be taught by using this constructivist teaching model. Along with this curriculum, planners may allocate more time for the subject of Chemistry.

6. Teachers should use the $5 \mathrm{E}$ instructional model because traditional instruction is less effective than the 5E instructional model. The function of the teacher is to facilitate and guide inquiry-based learning, so students uncover their misconceptions related to a particular concept and amend them appropriately.

7. Boys in college at the higher secondary level should properly be guided for a scientific inquiry approach. Inquiry-based learning needs a more decent and composed attitude. Therefore, boys' interest towards science may be improved by guiding and leading them towards technical learning with a positive and more focused approach.

\section{REFERENCES}

Alsop, S., Bencze, L. \& Pedretti, E. (2005). Analyzing exemplary science teaching: theoretical lenses and a spectrum of possibilities for practice. London: Open University Press. 
Bybee, R. W. (2009). The BSCS 5E instructional model and 21st-century skills. Colorado Springs, $C O: B S C S$.

Cakir, N. K. (2017). Effect of 5E learning model on academic achievement, attitude, and science process skills: Meta-analysis study. Journal of Education and Training Studies, 5(11), 157-170.

Calık, M., Ayas, A., Coll, R. K., Ünal, S., \& Coştu, B. (2007). Investigating the effectiveness of a constructivist-based teaching model on student understanding of the dissolution of gases in liquids. Journal of Science Education and Technology, 16(3), 257-270.

Ceylan, E. (2008). Effects of 5E learning cycle model on understanding of state of matter and solubility concepts. Unpublished Doctor Thesis, Orta Dogu Teknik University, Institute of Science and Technology, Ankara.

Daşdemir, İ. (2017). The effect of the 5e instructional model enriched with cooperative learning and animations on seventh-grade students' academic achievement and scientific attitudes. International Electronic Journal of Elementary Education, 9(1), 21.

Duran, L. B., \& Duran, E. (2004). The 5E Instructional Model: A Learning Cycle Approach for Inquiry-Based Science Teaching. Science Education Review, 3(2), 49-58.

Fazelian, P., \& Soraghi, S. (2010). The effect of 5E instructional design model on learning and retention of sciences for middle class students. Procedia-Social and Behavioral Sciences, 5, 140-143.

Johnstone, A.H. (1984). Macro and microchemistry.SchoolScienceReview, 64,377- 379.

Khan, A. S. (2011). Existing Level of Understanding of Concepts in The Subject of Chemistry Among Class IX Students and Effects of Teaching Chemistry Through "Concept Formation Teaching Model" On Students' Achievement (Doctoral dissertation, International Islamic University Islamabad, Pakistan).

Kilavuz, Y. E. L. İ. Z. (2005). The effects of 5E learning cycle model based on constructivist theory on tenth grade students' understanding of acid-base concepts. Middle East Technical University, Turkey.

Mari, J. S. (2012). Gender related differences in acquisition of formal reasoning schemata: pedagogic implication of teaching chemistry using process-based approaches. International Journal for Cross-Disciplinary Subjects in Education (IJCDSE), 2(2), 993 997.

Metin, M., Coskun, K., Birisci, S., \& Yilmaz, G. K. (2011). Opinions of prospective teachers about utilizing the 5E instructional model. Energy Educ Sci Technol Part B, 3, 411-422.

Ross, K., Lakin, L., McKechnie, J., \& Baker, J. (2010). Teaching secondary science: Constructing meaning and developing understanding. Routledge.

Santrock, J. W. (2007). Educational psychology, classroom update: preparing for praxis TM and practice. New York: McGraw Hill Companies.

Shaheen, M. N. U. K., \& Kayani, M. M. (2015). Improving students' achievement in biology using 7e instructional model: an experimental study. Mediterranean Journal of Social Sciences, 6(4), 471.

Sliwka, (2003) Chemistry: Why the Subject is Difficult?", (http://www.sciencedirect.com/science/article/pii/S0187893X17301581)

Springer, M. T. (2014). Improving students' understanding of molecular structure through broad-based use of computer models in the undergraduate organic chemistry lecture. Journal of Chemical Education, 91(8), 1162-1168. 
PJER, Vol 3, Issue 2 (2020)

$5 \mathrm{E}$ instructional model...

Taber, K. \& Coll, R. (2002). Bonding. In J. K. Gilbert, O. D. Jong, R. Justy, D.F., Treagust, \& J.H. Van Driel (eds.), Chemical education: Towards research-based practice, pp. 213-234. Dordrecht Kluwer.

Taber, K.S. (2001b). The mismatch between assumed prior knowledge and the learners' conceptions: A typology of learning impediments. Educational Studies,27(2),159-171.

Ürey, M., \& Çalik, M. (2008, December). Combining different conceptual change methods within 5E model: A sample teaching design of' cell' concept and its organelles. In AsiaPacific Forum on Science Learning \& Teaching (Vol. 9, No. 2).

Wigfield, A., Eccles, J. S., Schiefele, U., Roeser, R. W., \& Davis-Kean, P. (2007). Development of achievement motivation. Handbook of child psychology. 